\title{
Framing Disease, Ageing and Death in Popular Science Journalism
}

\begin{abstract}
This paper characterizes the dominant frames in popular science-oriented reports devoted to disease, ageing and death. In popular science journalism, framing often consists in the discursive construction of newsworthiness, i.e., foregrounding features of events/issues considered by science editors to be relevant or attractive for audiences, despite the alienating nature of some types of news. A sample of most-read health-related articles from New Scientist (2013-2015) is subjected to content analysis, keyness analysis, concordance analysis and news value analysis to demonstrate how bioscience tends to be framed through consistent and strategic linguistic choices. The analyses reveal that most frames for disease, ageing and death in popular science coverage work as vehicles for the celebration of medical science as a domain of reporting, and thus forward the media outlet's market-driven agenda rather than discuss the deeper implications of bioscientific findings.
\end{abstract}

\section{Keywords}

Framing; popular science journalism; keyness analysis; health-related news articles; New Scientist

\section{Introduction}

The concept of framing is used to highlight "persistent selection, emphasis and exclusion" in communication (Gitlin 1980: 7). While framing social reality people comprehend, negotiate and manage it. Frames are also sometimes defined as "cognitive windows" through which readers follow stories (Pan and Kosicki 1993: 59) or "maps" which they use while travelling through multiple realities (Gamson 1992: 117). According to Kitzinger (2007: 133), "framing refers to the 
process whereby we organize reality (...). The term is used to refer to how we interpret our everyday encounters with the world around us. It is also used to refer to how (...) a newspaper frames a story." Framing analysis can be seen as part of critical discourse analysis, as it reveals "the way in which content of the text is presented to its audience, and the sort of perspective, angle and slant the writer or speaker is taking. Related to this is what is foregrounded and what is backgrounded in the text; that is, what the author has chosen to emphasize or de-emphasize" (Paltridge 2013: 100). Media framing is a process that leads news readers to accept one meaning over another, or provides a consistent, even though simplified or biased, understanding of an issue.

Science journalism has evolved into a discursive domain where science-related content is expressed in ways that are accessible to a broad public rather than to a narrow elite. In addition to institutional or third-sector science popularization (or PR) campaigns, science journalism is mostly done by commercial media outlets that capitalize on the mass-appeal of science news. Similarly as in other domains of popularity-driven journalism, popular science reporting includes foregrounding perspectives, representations or features of science considered by science editors to be attractive for audiences. This involves deploying some discursive strategies aimed at presenting news as newsworthy, relevant and entertaining (Bednarek and Caple 2012; 2014; Molek-Kozakowska 2015; 2016). This study is based on the assumption that the construction of newsworthiness in science journalism is realized through framing science-related events with strategically chosen language resources to foreground a particular aspect or to take an angle to engage the target readers.

This paper aims to characterize the dominant frames in reports devoted to disease, ageing and death, despite the alienating nature of such topics. The choice of this thematic domain is not incidental: biomedical coverage has displaced other domains of reporting when it comes to attracting readers' attention, as medical progress has speeded up in unprecedented ways while the developed societies have grown more health-aware (Weitkamp 2003). Recent research on science-related coverage indicates a gradual reorientation away from physics, astrophysics, chemistry and engineering (popular at the time of nuclear proliferation, arms race and space exploration in the 1960s and 1970s) towards biology, medicine and biotechnology by the end of the twentieth century (Bauer 1998; Calsamiglia and van Dijk 2004; Bucci and Mazzolini 2007). Especially prominent have been stories involving news on AIDS and other epidemics, sequencing of the genome, advances in neuroscience and stem cell research, and the development of genetically modified organisms. Many mainstream news outlets have started to feature a regular "biomedicine/health" column or supplement and even made scientific news items appear in front pages. Biomedical issues are now regarded as being of high relevance to news consumers and this is used to attract a broader segment of readers who might be interested health-oriented lifestyle choices (Bucci and Mazzolini 2007).

The overall approach applied in this study is an adaptation of the newsworthiness framework that has been applied in news discourse studies (cf. Bednarek and 
Caple 2012, 2014). The material subjected to a critical framing analysis is a collection of 54 most-read articles (according to online traffic) sampled from the website of the popular international science magazine New Scientist between late 2013 and mid-2015. The texts are subjected to content analysis, keyness analysis, concordance analysis and newsworthiness analysis in order to identify the discursive strategies that function as framing devices which highlight the relevance of the coverage adding an element of entertainment (drama, mystery and speculation). The analyses reveal that some frames for disease, ageing and death in popular science coverage work as vehicles for the celebration of medical science as a domain of reporting, and thus might forward the outlet's market-driven agenda rather than enhance the public understanding of biotechnology and medicine.

\section{Discursive conventions of popular science journalism}

Journalism, at any point in time, can be perceived as a set of dominant conventions and inherited traditions for relating information within a particular institutional framework and with the aid of available technologies of mediation (Conboy 2011). That is why scholars need to problematize any preconceptions about the current state of the news media, acknowledging the complex constellation of economic factors, technological developments, political influences and cultural expectations that have oriented journalism towards a popular, mass-appeal medium. ${ }^{1}$ Although "popular journalism" is often viewed in terms of the gradual shift in content and focus of presented news items towards more human-interest, entertaining soft news, scandal and drama (McLachlan and Golding 2000), there has also been a significant change of style (Bell 1991; Fowler 1991; Conboy 2006). It has been noted, for example, that popular journalism involves not only shorter texts, more visuals and emotional headlines, but also more consumerismoriented features, more personalization of reporting and domestication of abstract issues, more dialogical formats, as well as more "journalist-dominated points of view" instead of balanced expert or witness accounts (Conboy 2011: 119).

However, stylistic facets of popular science reporting had not been systematically explored until recently. The role of language in representing or framing science in mass-appeal, market-driven, commercial context (rather than in institutional popularization activities) would require to be grasped more precisely, given its social relevance. Science journalism can no longer be claimed to have remained untouched by this larger stylistic shift: first indignant at the trivialization and simplification of news, science writers distanced themselves from popular coverage, before finally incorporating some of its features (Bowler 2009; Broks 2006). These new features include looking for "sellable stories," selection and framing of science news, as well as brevity and color in reporting (cf. Bauer and Gregory 2007).

To bear relevance to audiences, and to sell, news items have to fulfill some criteria of newsworthiness. Although the concept of newsworthiness (news value) 
has so far been applied to offer a systematic account of mainstream news discourse, it is productive in the study of science journalism too, as it enables looking at how market-driven agendas of media outlets influence not only the professional practices but also the textual outcomes of science journalism (Molek-Kozakowska 2016). This study will adopt the discursive approach to news values, as represented by Bednarek and Caple (2012: 41-44), who list such news values as negativity (i.e., negative aspects of events), timeliness (i.e., temporal relevance), proximity (i.e., geographical/cultural nearness), prominence (i.e., status/eliteness), consonance (i.e., alignment with expectations/stereotypes), impact (i.e., effects), novelty (i.e., newness/unexpectedness), superlativeness (i.e., large scale/ scope/intensity), and personalization (i.e., human aspects), and demonstrate how these values tend to be projected through journalists' choices in language and image, rather than being inherent attributes of events.

As negativity seems to be important to create newsworthiness, there is some evidence that mainstream news media have framed medical and biotechnological topics in critical and challenging ways, often accusing scientists of unethical and harmful activities. The negative framings of science in the media can be divided into five major types, according to Fjaestad (2007: 127)

Firstly, scientists sometimes create dangerous knowledge and products (e.g., weapons, toxins, genetic engineering). Secondly, scientists sometimes use methods that can be unethical or even illegal (e.g., painful experiments on animals, humans as guinea pigs, research on aborted fetuses, integritythreatening registers of individuals, also accepting financing from questionable partisan organizations, and instances of self-enrichment and downright fraud). Thirdly, scientists sometimes waste public funds on meaningless projects. Fourthly, scientists sometimes express opposite opinions on important matters; each of them claims to be right and on the other hand, dissident scientists are sometimes stigmatized by mainstream scientists. And finally, scientists sometimes withhold and repress information that ought to be made public.

One can infer that these framings in the mainstream news outlets can give biomedical coverage an aura of negativity and controversy that attracts attention. This, however, would not be productive in a science-exclusive outlet (e.g. the New Scientist), since it could decrease readers' appreciation and engagement. By contrast, with less demanding content and more positive, celebratory style, popular science journalism seems to be an alternative for audiences yearning for breakthroughs and more certainty about health-related issues. However, uncritically celebrating science may demobilize citizens from considering science funding policies and help to legitimize science-related activities without due evaluation of their merits.

Finally, science newsworthiness may also be rooted in a discursive oscillation between "the rhetoric of hope" and "the rhetoric of fear" (Kitzinger and Williams 
2005). Arguably, it might be claimed that vocabularies, metaphors and images that both highlight risks and celebrate benefits in science reporting represent what Jensen terms "a framing device that science journalists use to the detriment of a clear and coherent presentation of a controversial scientific development and its realistic implications" (2012: 44).

\section{Frames in the coverage of bio-medical research}

Extant studies on the mediated representations of biotechnological research explore, among others, the coverage of the new pandemics, human genome, nanotechnology, genetically modified organisms, neuroscience, cancer research, and embryo stem cell research or therapeutic cloning. Some studies reveal how the knowledge of the given issue is shaped for public understanding and acceptance through discursive devices and discuss the possible implications of such portrayals. For example, Calsamiglia and van Dijk (2004) demonstrate how the representation of the human genome is shaped in the popularizations available in the Spanish press. By referring to epistemic universals, common-sense schemas, and tangible metaphors, reporters frame the sequencing of the human genome as a process of "decoding a hidden message," which results in geneticists being finally able to "read it like a text." With this semi-technical and culturally acceptable metaphorical representation, it is possible to elicit public acclaim not only for the project but also for genetics as a discipline and genetic engineering as a therapeutic solution. However, according to a different study on a televised documentary on cancer therapies in the UK (Potter, Wetherell and Chitty 1991), public expectations as regards advances in cancer research may well be inflated by charity organizations, which have to justify collecting money for their causes. The use of quantification rhetoric to frame cancer research as advancing (despite the lack of new available therapies) has been exposed in the study.

Through a study on the levels of acceptance of medical and agricultural GM technologies in Denmark, Mielby, Sandoe and Lassen (2012) have found that for the publics whose level of knowledge and education is higher, acceptance correlates with the judgments of relative risks and benefits of a given technology. Meanwhile, receivers with lower levels of knowledge of the issue tend to express their acceptance depending on their perception of how "natural" or "unnatural" a given biotechnology is presented. It seems that the more the public knows about the biotechnology the more complex frames would be needed to discuss it. In a similar vein, positive attitudes towards nanotechnologies have taken root in Germany, as reporters tended to frame the scientists' inventions in terms of possible benefits rather than risks, and when they associated them with commonly held beliefs and cherished values, such as progress and welfare (Guenther and Ruhrmann 2013). The work of the scientists is also likely to be celebrated within the coverage of epidemics, particularly if the popular representations of diseases metaphorically frame them as fighting viral "adversaries," "attackers," "criminals," 
or "murderers," or as the ones who try to stop the "flood" or "intercept dangerous viral parcels," as was documented by Dobrić and Weder (2016) in the case of the mediated conceptualizations of flu pandemics within 1990-2010.

The uptake of science journalism as regards the key bio-controversies needs to be closely monitored. In a review article on how neuroscience influences common conceptions of personhood and human agency, O'Connor and Joffe (2013) show that the public awareness of neuroscience is relatively low (even though media frames of neuroscientific advances present them as a revolutionary transition from psychological to biological understanding of the self), and the ideas that happen to be assimilated tend to reinforce old folk-psychological conceptions rather than challenge them. What this study also shows is that the proliferation of the images of brain scans in the media is motivated by their perceived "truth value" and is used to enhance the credibility of journalism (O'Connor and Joffe 2013). Also, the public is shown to be mostly interested in everyday applications of neuroscience (e.g., criminal uses for lie detection, applications in marketing and public policy), which means that to engage audiences, science news items should be framed as offering concrete solutions (even though available only in the future) and not as an unresolved scholarly debate.

By contrast, when the public does pay attention to science news, the reporting can do some deeply ideological work. Kitzinger and Williams (2005) use frame analysis and detailed linguistic analysis to illustrate how the framing of embryo stem cell research in British national press and televised reports in 2000 helped to mitigate doubts about this controversial biotechnological procedure (also known as therapeutic cloning). The media materials abounded in hype frames that heralded innovation and breakthrough, authority appeals foregrounding the approving collective opinion of the scientific community, and emotional appeals on behalf of the patients with incurable diseases, who would profit the most from the future possibilities of organ replacement. The authors point to the fact that the stem cell regulations ultimately accepted by the government were compatible with the dominant frames and assessments foregrounded in the mainstream media.

In summary, it can be observed that biomedical research tends to be conventionally framed in a range of ways: the advances in biotechnology and medicine can be represented as BENEFIT ${ }^{2}$ or RISK, as BREAKTHROUGH or FAILURE, and as REVOLUTION or in terms of CONTINUITY. At the same time the state of knowledge in a particular field can be framed as unresolved DEBATE or, more often, as advancing towards APPLICATION in a foreseeable future. As regards guiding public acceptance, useful frames involve (UN)NATURALNESS or (UN) DESIRABILITY of specific inventions. These typically occurring frames will be traced in the sample material in the following sections; at the same time, evidence for other framings will also be sought. 


\section{Framing disease, ageing and death}

\subsection{Material}

The sample for this analysis of the dominant frames of disease, ageing and death in popular science journalism had been collected for 22 months (between October 2013 and July $201^{5}$ ) from the online version of one of the most widely circulated international science magazines - New Scientist (NS henceforth). ${ }^{3}$ The main selection criterion was that the text should have been popular with readers and generated their engagement. Thus, instead of a random sample from the health column, the corpus was created by downloading articles every week from the list of five "most read" articles as listed on the NS website. Sometimes the list did not feature any medicine-oriented items, sometimes there were a few articles, sometimes the same article persisted in the list for a few weeks (but was included only once). The text was included in the sample if its headline included such terms as disease, death or ageing, or a specific term for a disease. Articles on drugs, therapies, discoveries and experiments related to treating diseases and improving health were also included. The sample is thus made up of 54 articles (listed in the appendix) with the total word count of over 26,700 .

\subsection{Content analysis}

The first step in the analysis was to code all articles (whole texts) with respect to dominant content categories. The total sample $(n=54)$ has been shown as inclusive of one large category of content, namely "announcing new drugs/therapies" $(n=30)$ and one smaller content category, namely "explaining causes of diseases/designing diagnostic tools" $(\mathrm{n}=17)$. This division could be roughly mapped onto the distinction between two frames: APPLICATION and DEBATE, with the number of the former twice as large as of the latter. This indicates the NS readers' preferences for learning about actual solutions to health problems when it comes to selecting news, and confirms the role of the APPLICATION frame as regards forging engagement. The remaining articles $(\mathrm{n}=7)$ consist of miscellaneous content, such as "discussing psychological/social aspects of illness, or relating individual's stories of dealing with disease." The articles were also coded for the prevalent evaluation of the subject, thus yielding the following distribution: positive news (BREAKTHROUGH) - 33 items, neutral news - 11 items, negative news (FAILURE) - 10 items (validated by two coders). Importantly, the dominant evaluative stance could be usually determined already at the level of headline/ lead, which confirms the significance of headlines for framing the reception of popular scientific news (cf. Molek-Kozakowska 2016).

Also, according to the currently held evidence-based model of medicine, medical discourse distinguishes between disease and illness. Disease is a term that denotes a state of presence of manifestations indicating a given pathological change at various levels of medical description (e.g., whole patient, part of the 
body, system, organ, tissue, cell, molecule), while illness is defined as a subjective perception of the state by the patient. This model privileges the discursive representation of disease (rather than illness) and is noted for the "evacuation" of the patient as a person from presentations of medical cases, mainly by focusing on organs, symptoms, procedures and outcomes (cf. Murawska 2011: 191-192). The conducted content analysis confirms that NS's coverage of medical issues reproduces the model, as it also focuses on diseases rather than people who are affected by them (with only a handful of texts dealing with individuals experiencing illness in a peculiar way, e.g., (15) and (43)). Many articles also foreground the activity and agency of scientists who are shown to relentlessly and creatively manipulate data and substances, and conduct experiments to be able to diagnose, control or eradicate diseases, slow ageing and save lives (cf. CONTINUITY, DESIRABILITY frames).

\subsection{Keyness analysis}

Keyness is a parameter of the relative salience of a term in a given sample vis-àvis a reference corpus ( $\mathrm{RC})$ - here the British National Corpus. Table 1 illustrates the 50 first keywords in the sample (and the term death) sorted in the order of decreasing positive keyness value (last column). The baseline frequency included was 10 occurrences in the sample to exclude cases when multiple occurrences of the term in one article could skew the results. This ensures a shorter but more representative list of items that characterize the sample.

Table 1. Keyness values for NS sample (WordSmith Tools 4.0)

\begin{tabular}{|l|l|l|l|l|l|l|}
\hline & Word & Freq. & $\%$ & RC Freq. & RC $\%$ & Keyness $(+)$ \\
\hline 1. & CELLS & 88 & 0.5146 & 7646 & & $\mathbf{5 6 5 . 9 6}$ \\
\hline 2. & BLOOD & 67 & 0.3918 & 9767 & & $\mathbf{3 6 3 . 1 4}$ \\
\hline 3. & BRAIN & 55 & 0.3216 & 4580 & & $\mathbf{3 5 8 . 2}$ \\
\hline 4. & VIRUS & 32 & 0.1871 & 1492 & & $\mathbf{2 4 4 . 7 8}$ \\
\hline 5. & SAYS & 78 & 0.4561 & 39363 & 0.0396 & $\mathbf{2 3 9 . 0 5}$ \\
\hline 6. & DRUG & 39 & 0.2281 & 4987 & & $\mathbf{2 2 1 . 2 7}$ \\
\hline 7. & CANCER & 35 & 0.2047 & 4212 & & $\mathbf{2 0 2 . 7}$ \\
\hline 8. & ALZHEIMER'S & 19 & 0.1111 & 197 & & $\mathbf{2 0 0 . 8 5}$ \\
\hline 9. & DIABETES & 23 & 0.1345 & 652 & & $\mathbf{1 9 8 . 3 6}$ \\
\hline 10. & CANNABIS & 18 & 0.1053 & 414 & & $\mathbf{1 6 2 . 5 8}$ \\
\hline 11. & PEOPLE & 99 & 0.5789 & 116196 & 0.1168 & $\mathbf{1 5 9 . 1 7}$ \\
\hline 12. & DRUGS & 30 & 0.1754 & 5304 & & $\mathbf{1 5 1 . 3 2}$ \\
\hline 13. & DISEASE & 33 & 0.193 & 8869 & & $\mathbf{1 3 9 . 9 2}$ \\
\hline 14. & FAT & 27 & 0.1579 & 4491 & & $\mathbf{1 3 9 . 3 7}$ \\
\hline 15. & MICE & 18 & 0.1053 & 1020 & & $\mathbf{1 3 0 . 7 8}$ \\
\hline 16. & RESEARCHERS & 21 & 0.1228 & 2496 & & $\mathbf{1 2 2 . 1 2}$ \\
\hline
\end{tabular}




\begin{tabular}{|c|c|c|c|c|c|c|}
\hline 17. & SYMPTOMS & 22 & 0.1286 & 3119 & & 120.38 \\
\hline 18. & FATS & 13 & 0.076 & 276 & & 119.44 \\
\hline 19. & VIRUSES & 14 & 0.0819 & 486 & & 115.18 \\
\hline 20. & TISSUE & 19 & 0.1111 & 2043 & & 114.2 \\
\hline 21. & IMMUNE & 16 & 0.0936 & 968 & & 114.2 \\
\hline 22. & BODY & 40 & 0.2339 & 24211 & 0.0243 & 109.37 \\
\hline 23. & UNIVERSITY & 34 & 0.1988 & 15780 & 0.0159 & 109.35 \\
\hline 24. & $A G E I N G$ & 16 & 0.0936 & 1254 & & 106.07 \\
\hline 25. & STEM & 16 & 0.0936 & 1258 & & 105.97 \\
\hline 26. & FATIGUE & 12 & 0.0702 & 485 & & 95.145 \\
\hline 27. & TRANSPLANT & 12 & 0.0702 & 493 & & 94.76 \\
\hline 28. & INFLAMMATION & 11 & 0.0643 & 456 & & 86.669 \\
\hline 29. & CELL & 20 & 0.117 & 5418 & & 84.484 \\
\hline 30. & ANTIBODIES & 12 & 0.0702 & 777 & & 84.045 \\
\hline 31. & GLUCOSE & 11 & 0.0643 & 602 & & 80.671 \\
\hline 32. & SURGERY & 15 & 0.0877 & 2636 & & 75.822 \\
\hline 33. & DNA & 16 & 0.0936 & 3369 & & 75.299 \\
\hline 34. & TREATMENT & 24 & 0.1403 & 12124 & 0.0122 & 73.447 \\
\hline 35. & TRIAL & 19 & 0.1111 & 6381 & & 72.531 \\
\hline 36. & FATTY & 10 & 0.0585 & 585 & & 72.028 \\
\hline 37. & INSULIN & 10 & 0.0585 & 631 & & 70.543 \\
\hline 38. & CALIFORNIA & 13 & 0.076 & 2070 & & 68.194 \\
\hline 39. & BREAST & 12 & 0.0702 & 1621 & & 66.782 \\
\hline 40. & PROTEIN & 14 & 0.0819 & 2898 & & 66.344 \\
\hline 41. & MUSCLE & 12 & 0.0702 & 1740 & & 65.128 \\
\hline 42. & TREATMENTS & 10 & 0.0585 & 868 & & 64.289 \\
\hline 43. & DAMAGE & 19 & 0.1111 & 8313 & & 63.156 \\
\hline 44. & HUMAN & 26 & 0.152 & 19275 & 0.0194 & 61.749 \\
\hline 45. & CHRONIC & 11 & 0.0643 & 1689 & & $\mathbf{5 8 . 4 7 7}$ \\
\hline 46. & CONDITION & 18 & 0.1053 & 8312 & & 58.042 \\
\hline 47. & SYNDROME & 10 & 0.0585 & 1222 & & 57.603 \\
\hline 48. & COGNITIVE & 10 & 0.0585 & 1226 & & $\mathbf{5 7 . 5 3 9}$ \\
\hline 49. & STUDY & 25 & 0.1462 & 21844 & 0.022 & 52.298 \\
\hline 50. & TEAM... & 23 & 0.1345 & 18307 & 0.0184 & 51.785 \\
\hline 55. & DEATH & 22 & 01289 & 19884 & 0.02 & 44.835 \\
\hline
\end{tabular}

The analysis of keyness values in the sample reveals the marked salience of medical and biological terminology, which, nevertheless, is part of general science literacy, rather than experts' jargon. Apart from biomedical register, with terms denoting parts of the human body, pathogens, conditions and treatments, there are also words typical of journalistic discourse (e.g., attribution of sources with says), as well as items that describe scientists' activities and pertain to doing research (researchers, study, team). The keyness values of the words disease, ageing and death are high $(139.92 ; 106.07$ and 44.835 respectively). These and many other 
key terms may have negative valence because they denote UNDESIRABLE or UNNATURAL processes or conditions; however, when compared with the results of content analysis (above), many articles in fact use them to frame scientific findings in opposition to these and show how researchers and doctors work to help patients counter these undesirable conditions.

\subsection{Concordance analysis}

Concordance analysis enables a less atomized and decontextualized analysis of "semantic prosody" of selected terms. It can point to salient meanings and strategic evaluation-laden collocations and may even reveal the prevalent ideological stances behind the routine usages of salient terms. For example, in the case of the word ageing $(\mathrm{n}=16)$ the most common collocations with verbs include slow down, explain, tackle and contribute to. This demonstrates that many articles on aging are actually devoted to elucidating the biological/biochemical mechanisms of aging in order to intervene in them to counter ageing. Ageing is represented negatively: it is either pathologized as a collection of diseases, or simply seen as an unwanted process that scientists should strive to understand to a sufficient degree to be able to slow or stop it. Ageing, framed as an UNDESIRABLE phenomenon to be first explained and then managed, is discussed in NS both in the context of DEBATE (free radicals theory of ageing) and in terms of APPLICATION (longevity drugs that can fix oxidative damage, exercises that prevent muscle atrophy and thus metabolic degeneration).

The word death $(\mathrm{n}=22)$ appears only in few articles, including one that extensively discusses the psychological aspects and cultural rituals related to perceiving death and dying (48). The existential questions tackled in the article include accepting death, coming to terms with death, preoccupation with death, sanitizing death in order to help patients with incurable diseases and their families to discuss their predicament. Concordance analysis also reveals the tendency to use the opposition between life and death, or life vs. death in headlines and leads to attract attention. The term death often appears in various collocations when causes of death are discussed (diseases, infections, adverse effects, terminal conditions), as well as when risks and lifestyles that result in death are reported on (smoking cannabis) (cf. RISK frame). In these contexts, the word is used to magnify unwanted consequences to legitimate scientists' efforts and funding to study a given phenomenon. For example, studying the effects of cannabis or plastic surgery or discussing depression is legitimized when incidental deaths are mentioned to dramatize the issues (cf. UNDESIRABILITY frame). Unexpectedly, the word does not feature too prominently in articles on Ebola or some articles about cancer, perhaps not to alienate the readers. In such contexts, mass life loss or implication of terminal condition is already a part of readers' background knowledge that does not need to be articulated.

Concordance analysis of the term disease $(n=33)$ demonstrates a variety of common pre-modifications (heart, liver, skin, autoimmune, Alzheimer's, incur- 
able, rare), as well as such positive collocations as treating, alleviating, diagnosing, managing, slowing the progression of. Such collocates constitute frames that mostly inspire optimism and hope for the ability of bioscientists to control or eradicate some diseases (BENEFIT, BREAKTHROUGH frames). However, the word disease is often a relatively abstract hyperonym, and more attention should be paid to how particular diseases are represented in the sample. As a result, concordances of diabetes $(\mathrm{n}=23)$, Alzheimer's $(\mathrm{n}=19)$ and cancer $(\mathrm{n}=35)$ have also been studied.

The term diabetes occurs in common collocations describing diabetes'types, drugs, medication, risks and causes. One article ventures to claim a symptomatic similarity between diabetes and Alzheimer's disease and discusses how the doctors' knowledge of diabetes management and medication can be used to diagnose early onsets of Alzheimer's (7). As diabetes is a complex condition that affects the whole body and that cannot be cured, it is not surprising that the most common collocations of diabetes with verbs are managing, assisting, controlling and preventing. In one article a breakthrough study is announced with information that diabetes can be fought with light (2). Here, one can find the only instances of collocates such as healing/fighting diabetes (in mice). One more article - Bionic pancreas frees people from shackles of diabetes (24) - uses an elaborate metaphorical construction to suggest that people can be cured of diabetes, which on closer reading turns out to be about freeing them only from the exhausting regime of glucose level monitoring, and thus realizes CONTINUITY rather than REVO$L U T I O N$ frame. ${ }^{4}$ It can be concluded that the gradual progress in the studies on diabetes, which is a prevalent but relatively undramatic condition, is framed as newsworthy through strategically applied collocations and rhetorical devices.

As with diabetes, Alzheimer's disease has high keyness and relative frequency featured in the sample. The medical progress on diagnosis and treatment of Alzheimer's (which is tightly related to ageing processes of the human brain) is reported in four articles with intimations of successful experimental therapies. It may be striking to note that the term Alzheimer's appears in one sentence with young blood transfusion, rejuvenation and organ donation. This frames biomedical research as going to great lengths to try out various exceptional measures to slow down the progressive degenerative process resulting in Alzheimer's and invokes APPLICATION and REVOLUTION frames slightly misleadingly.

Although the word cancer scores the highest frequencies in the sample, it is worth remembering that it relates to various conditions, as the following most common pre-modifiers demonstrate: breast, blood, bone, brain, fat tissue. Apparently, cancer research reported in NS is mostly related to studies of biochemical and genetic character. Thus frequent collocations involve cancer cells, genes, chromosomes, or scanning for cancer (spreading). Attention is devoted to uncovering the cellular mechanisms within tumors and manipulating genes responsible for cell/tissue functioning to stop or hinder the growth of tumors. Thus the expression beating cancer or a metaphorical formulation that cancer meets its nemesis is linked less to cancer surgery or chemotherapy, and more to genetic engineering 
(REVOLUTION frame intertwined with RISK and BENEFIT frames). This seems to indicate that cancer research is framed as cutting-edge discipline of genetic science and that biotechnologists are learning how to reprogram our cells to stop turning tumorous (cf. Cancer meets its nemesis in reprogrammed blood cells (6)).

\subsection{Newsworthiness analysis}

The above quantitative findings confirm that a variety of frames can be used to engage readers. This qualitative part of the analysis of the texts verifies the observations with attention to news values that function as frames to construct events discursively as worth readers' engagement. A close reading of the sample reveals that articles on diseases build newsworthiness through novelty, timeliness or superlativeness.

Novelty is signalled relatively early in the texts, and it is very prominent in the sample. One could even conclude that the main rationale for the choice of publishing/reading an item is to understand it as novel, wide-ranging and successful (all emphases mine):

(1) For the first time, new human hairs have been coaxed into growing from specialized skin cells that can be multiplied in number. (1)

(2) The discovery is the first evidence that it may be possible to revert the human brain to a childlike state, enabling us to treat disorders and unlock skills that are difficult, if not impossible, to acquire beyond a certain age. (9)

(3) The world's first blood test to predict Alzheimer's disease before symptoms occur has been developed. (14)

(4) Vaginas grown in a lab from the recipients' own cells have been successfully transferred to the body for the first time. (20)

(5) A novel scanning technique is enabling researchers to pinpoint where in the body HIV is lurking. (42)

One could argue that each scientific activity/study/publication is novel in some way; however, novelty in biomedical coverage is framed as more significant, as it carries a promise of saved lives and cured populations. This is how such a study can eventually be framed as a BREAKTHROUGH. Signalling novelty means introducing audiences to cutting-edge science that solves health-related problems large or small, and, even though the coverage only intimates future possibilities, it can be read as a celebration of the idea that humans will control disease (BEN$E F I T)$. Some of the developments are additionally framed as unexpected and thus scientific research is overlaid with the aura of MYSTERY. 
(6) Having type 2 diabetes may mean you are already on the path to Alzheimer's. This startling claim comes from a study linking the two diseases more intimately than ever before. (5)

(7) It was as unexpected as it was tragic: children in northern Europe who got one particular vaccine against the 2009 swine flu pandemic were at a much higher risk of developing narcolepsy. (18)

Another common newsworthiness cue in the coverage of disease is realized through representations of timeliness (recent events or future developments).

(8) Light can now be used to heal diabetes in mice. (3)

(9) In two months'time, a group of profoundly deaf people could be able to hear again, thanks to the world's first gene therapy trial for deafness. (21)

(10) Taking the drugs could be counterproductive, especially for older people, suggests a study published yesterday. (26)

This discursive strategy is important to show how distant issues of lab experimentation may be relevant to larger publics. ${ }^{5}$ It has a potential of framing biomedical progress as radical and speedy (REVOLUTION) and its products as available and ready to take advantage of (APPLICATION), which in many cases is questionable, as the reports concern early findings and only speculate about future applications.

Superlativeness has been demonstrated as a prominent news value of popular journalism, which thrives on exaggeration and sensationalism (cf. Barnett 2008; Molek-Kozakowska 2013). The NS sample features words and phrases that represent extremity or project a sense of unusualness that borders on DRAMA:

(11) Five people with a type of blood cancer [...] were in remission following treatment with genetically engineered immune cells from their own blood. One person's tumors disappeared in just eight days. (6)

(12) Extraordinary stem cell method tested in human tissue. (10)

(13) It's neuroscience's final frontier. Tiny bubbles will open the blood-brain barrier to sneak drugs into tumors [...] If successful, the method would be a huge step in the treatment of pernicious brain diseases such as cancer, Parkinson's and Alzheimer's. (25)

(14) When chromosomes shatter, they sometimes reform into giant circular monsters. These beasts gobble up cancer genes, incorporate them into their DNA, and seed aggressive tumors. (38) 
Superlativeness is mostly constructed in the articles on new diagnostic tools or newly developed therapies. Although the usefulness and potential for application of these findings is yet to be determined, the intensifiers, adjectives and emotive nominals, sometimes collocated with verbs that vividly describe (threatening) physical activities (shatter, seed, sneak, gobble up) rather than abstract processes, introduce the imagery of scientific progress that exceeds our expectations and that should leave us in awe of the discoveries (REVOLUTION, BREAKTHROUGH).

Such impression is also created with the framing of bioscientific advances as having a large, even global, scale and significant consequences for millions of prospective patients:

(15) Last week, the scientific world was bowled over by a study in Nature showing that an acidic environment turned adult mouse cells into 'totipotent' stem cells - which can turn into any cell in the body or placenta. (10)

(16) Tiny bugs $[\ldots]$ may be causing an ancient skin disease that is estimated to affect between 5 and 20 per cent of people worldwide, and 16 million in the US alone. (16)

(17) Damiano, a biomedical engineer, decided to create a device that would help his child and millions of others better manage their disease. (24)

What is characteristic of the frames for the scope and scale of biotechnological advancements is the fact that such formulations are often mitigated with epistemic modality (note the uses of modal verbs can, may or would or verbs that have tentative meaning - show, estimate, help) to appear as credible at such a preliminary stage of research. Nevertheless, they enable editors to frame science as relevant (DESIRABILITY) to a large proportion of readers or the whole humanity.

If disease coverage is constructed as newsworthy with the construction of novelty, timeliness and superlativeness, then ageing is often represented with the frames that engender either consonance (18, 19, 20 below) or impact (21, 22, 23 below). The former anchor the reporting in the common knowledge about the body and the ageing processes (NATURALNESS), while that latter offer news on new means to be tried out to counter them and "rejuvenate" the human organism.

(18) Breasts typically age more quickly than the rest of the female body. So suggests a system that may be the most accurate way yet of identifying a person's age from a blood or tissue sample. (2)

(19) It could be the biggest killer you've never heard of: the weakening and loss of muscle that happens as we get older. However, the mechanisms behind muscle ageing are still poorly understood - although new research suggests it involves damage from free radicals. (32) 
(20) The number of eggs in a woman's ovaries could tell a lot more than just how fertile she is. It may provide a window onto how fast her cells are ageing and her risk of developing heart disease. (33)

(21) So suggests a discovery that highly diluted household bleach inhibits inflammation in the skin [...] might help protect skin from sun exposure, radiation therapy and even the natural ageing process. (4)

(22) It sounds like the dark plot of a vampire movie. In October, people with Alzheimer's disease will be injected with the blood of young people in the hope that it will reverse some of the damage caused by the condition. (30)

(23) Pill of super-protective 'heavy' fat may be key to eternal youth [...] For the first time next month, fats designed to reinforce our cells against agerelated damage will be given to people in a clinical trial. The participants have a rare genetic disorder, but if the treatment works for them, it could eventually help us all live longer, more youthful lives. (47)

Although it is less conspicuous in the sample, the coverage of news items related to ageing has a widespread target appeal - all people get old whereas not all get all the diseases covered by NS. However, the number of articles in the most-read sample is not substantial, which indicates that the readers may not feel that the topic merits too much attention or is relevant for them at the moment. The framing of ageing that can be detected in NS tends to represent it as something that is relatively poorly understood in terms of practical ways of slowing it down (DEBATE). Such framing does not inspire hope or enthusiasm for science, which perhaps explains its relatively low uptake. One exception to this rule is the overtone of hype in (23) where several linguistic choices (super-protective, eternal youth, for the first time, eventually) seem to misleadingly frame the finding as a BREAKTHROUGH.

Death in reporting is newsworthy per se, so mentioning it is often enough to dramatize and sensationalize the coverage, since all news of spreading epidemics, lethal substances or deadly pathogens guarantee readership. In bioscience journalism some types of research may be framed as more significant (news value of prominence) if they directly prevent death or save lives, as in

(24) Neither dead or alive, knife-wound or gunshot victims will be cooled down and placed in suspended animation later this month, as a groundbreaking emergency technique is tested out for the first time. (18)

(25) Deaths in Africa from Ebola reached 1013 earlier this week, with 1848 cases reported. [...] With all the activity on the ground in Africa $[\ldots]$ it was something of a surprise to find that the specific way Ebola kills has only just been discovered. (29) 
(26) Cancer is cruel: sometimes, life-saving surgery to cut out a tumor may be the very thing that spreads it to other parts of the body. Most people who die from cancer do so because their tumor has spread, or metastasised. Yet most of today's cancer drugs don't stop metastasis, they just kill any cancer cells they come into contact with. (44)

However, death is also framed in terms of the unknown: a MYSTERY that justifies bioscience as an ongoing project and ensures its eliteness as a domain of scientific inquiry.

(27) Death is the one certainty in life - a pioneering analysis of blood from one of the world's oldest and healthiest women has given clues to why it happens. (23)

(28) The first full post-mortems of people who died after smoking cannabis suggest that the drug can kill unaided. Cannabis has been known to cause death when laced with other substances, by triggering a heart condition or by causing respiratory cancers. But whether it can be directly lethal has remained unclear. (12)

(29) Retroviruses insert their genetic material into the cells of their human or animal host. At first, this causes disease and death. Over time, however, the host evolves resistance to the virus, allowing any DNA that has embedded itself into sperm or egg cells to be passed down to the next generation. (45)

In these contexts, the word death is used to magnify unwanted consequences of the lack of knowledge (UNDESIRABILITY), to celebrate scientists' laudable efforts (CONTINUITY) and, indirectly, to legitimate the costly enterprises to study particular conditions or processes hoping for a major BREAKTHROUGH.

\section{Conclusion}

Science in general and medical science in particular constitute prestigious domains in modern societies. Substantial funding is channelled to biomedical research and the role of experiments and innovations has increased (Gunnarsson 2013: 186). As medical scientists have become a specialist discourse community, the popularization of medical findings has been taken over by trained journalists, who have to mitigate the "scientificality" of academic medical writing and make it fit in with the palatable templates of popular journalism. Science writers and editors take some responsibility to relate new developments to increase the public understanding of bioscience and make readers more aware of the newest recommendations in health-related research. At the same time, commercial media 
outlets are hard-pressed to ensure readership, loyalty and continuous engagement of the public with their output. It is against such a dynamic institutional, professional and social background that this study aims to explore the current frames in popular science reporting on disease, ageing and death.

The paper reviews some of the available research on how biomedicine tends to be conventionally represented in the media in terms of three dominant approaches: (1) negative and critical assessments expressed by some quality publishers, which are on the wane as expensive investigative science journalism is reduced, (2) positive, even celebratory tones of some popular outlets that uncritically follow science PR and press releases, and (3) ambivalent or sensationalist representations that engender uncertainty and are designed to motivate readers to keep consuming science-related coverage. Then, a sample of most-read health-related articles devoted to disease, ageing and death from New Scientist is subjected to content analysis, keyness analysis and concordance analysis to grasp how bioscience tends to be framed with salient and strategic linguistic choices. The analyses reveal the dominance of fairly positive evaluations (DESIRABILITY, BENEFIT) despite the alienating nature of the subject matter, of celebratory frames (BREAKTHROUGH, REVOLUTION, APPLICATION), and representations of findings that rarely problematize the issues or foster reflective or critical attitudes among the reading public with few RISK or UNNATURALNESS frames. On the contrary, some frames overlay the coverage with the sense of uncertainty (MYSTERY) that only more effort on behalf of the scientists and more funding for experiments can help dispel (CONTINUITY).

Specifically, disease coverage is made newsworthy with reference to novelty, timeliness and superlativeness of the biomedical findings reported (BREAK$T H R O U G H)$. Articles on ageing frame the scientists' discoveries as consonant with folk knowledge and focused on impact/effects (NATURALNESS, BENEFIT). As regards the articles that make references to death, it is apparent that they capitalize on the prominence of the subject and result in highlighting the special status and acclaim accrued to biotechnology and medical sciences. The analysis reveals that most frames for disease, ageing and death in popular science coverage work as vehicles for the celebration of medical science as a domain of reporting, and thus forward the media outlet's market-driven agenda rather than discuss the deeper implications of scientific findings. The moral, social, economic and political consequences of bioscientific progress are rarely taken up. The coverage fails to position the reader as someone to be empowered to deliberate on the issue; rather the audience is to embrace and celebrate bioscience. These frames seem to be strategically designed to motivate continuous engagements with the outlet, a mechanism to rear loyal audiences (McManus 1994), who are shown as being in need of resolving their sense of uncertainty and uncontrollability of the implications of bioscientific progress and mitigating anxiety characteristic of postindustrial risk societies (Beck 1992).

The study follows the assumption that "media frames have a demonstrable, although not deterministic, impact on the public" (Kitzinger and Williams 2005: 
731), and aims to critically interrogate the dominant framings of biomedicine in popular science journalism. As it was limited to one established popularization outlet and to its most-read articles only, it was to provide a close analysis of the discursive strategies used to construct the newsworthiness of scientific reports through framing, and a discussion of implications of such prevalent framings of bioscience. It does not suggest that these are the only framings and trends in popular science journalism. Likewise, it does not suggest that all the audiences are prone to accepting such framings unreflectively. In fact, this is a starting point to designing reception studies that could verify if popular science writing indeed fosters readers' understanding of science and creates informed attitudes, or if it merely legitimizes science as a domain of social activity in order to entrench its own market positioning.

\section{Notes}

1 Although the origins of popular journalism go back to radical working-class papers of the early $20^{\text {th }}$ century, which offered "news digests in proletarian language" spiced up with entertainment and engaged in the "lived experience of the readers" (Conboy 2011: 110 111), with the launching of tabloids in the 1970s, popular journalism gradually turned away from left-wing politics and started to be characterized by narrow agendas, populist appeals, celebrity-oriented themes, exaggerated representations and raucous and aggressive style (Barnett 2008). This shift was said to depoliticize and misinform the public, and led to vociferous criticisms of the commercialized news industry and newsworthiness-driven popular journalism.

2 The notation of identified frames in italicized capitals is designed to help distinguish them from key terms.

3 In 2014, the Audit Bureau of Circulations estimated NS's global print circulation at 129,585 and its readership at 807,388 , while according to Adobe Reports \& Analytics, its online version was subject to over 8 million page impressions with over 3.6 million unique visitors. NS was listed as one of the top ten science-related periodicals in Australia, the UK and the US and offered an online database of over 100,000 articles. On social media, NS had $1.47 \mathrm{~m}+$ Twitter followers, 2.3m+ Facebook likes and 365,000+ Google + followers as of January 2015 (cf. http://mediacentre.newscientist.com/audience-and-brand).

$4 \quad$ This kind of metaphorical mapping may have a 'coercive' potential, cf. Molek-Kozakowska (2014).

5 A maneuver also called ‘temporal proximization' in Molek-Kozakowska (2015).

\section{References}

Barnett, Steven (2008) 'On the road to self-destruction.' British Journalism Review 17(1): 7-14.

Bauer, Martin W. (1998) 'The medicalization of science news: From the rocket-scalpel to the genemeteorite complex.' Social Science Information 37(4): 731-751.

Bauer, Martin W. and Jane Gregory (2007) 'From journalism to corporate communication in postwar Britain.' In: Bauer, Martin W. and Massimiano Bucchi (eds.) Journalism, Science and Society: Science Communication between News and Public Relations. London: Routledge, 33-52.

Beck, Ulrich (1992) Risk Society: Towards a New Modernity. London: Sage. 
Bednarek, Monika and Helen Caple (2012) News Discourse. London: Continuum.

Bednarek, Monika and Helen Caple (2014) 'Why do news values matter? Towards a new methodological framework for analyzing news discourse in Critical Discourse Analysis and beyond.' Discourse \& Society 25(2): 135-158.

Bell, Allan (1991) The Language of News Media. Oxford: Blackwell.

Bucchi, Massimiano and Renato G. Mazzolini (2007) 'Big science, little news. Science coverage in the Italian daily press, 1946-1997.' In: Bauer, Martin W. and Massimiano Bucchi (eds.) Journalism, Science and Society: Science Communication between News and Public Relations. London: Routledge, 53-70.

Bowler, Peter (2009) Science for All: The Popularization of Science in Early Twentieth Century. Chicago: Chicago University Press.

Broks, Peter (2006) Understanding Popular Science. Maidenhead: Open University Press.

Calsamiglia, Helen and Teun A. van Dijk (2004) 'Popularization discourse and knowledge about the genome.' Discourse and Society 15(4), 369-389.

Conboy, Martin (2006) Tabloid Britain: Constructing a Community through Language. London: Routledge.

Conboy, Martin (2011) Journalism in Britain: A Historical Introduction. London: Sage.

Dobrić, Nikola and Franzisca Weder (2016) 'Media conceptualizing illness - the case of flu.' Continuum: Journal of Media \& Cultural Studies 30(1): 126-142.

Fjaestad, Bjorn (2007) 'Why journalists report science as they do.' In: Bauer, Martin W. and Massimiano Bucchi (eds.) Journalism, Science and Society: Science Communication between News and Public Relations. London: Routledge, 123-131.

Fowler, Roger (1991) Language in the News: Discourse and Ideology in the Press. London: Psychology Press.

Gamson, William A. (1992) Talking Politics. New York: Cambridge University Press.

Gitlin, Tod (1980) The Whole World is Watching: Mass Media in the Making and Unmaking of the New Left. Berkeley: University of California Press.

Guenther, Lars and Georg Ruhrmann (2013) 'Science journalists' selection criteria and depiction of nanotechnology in German media.' Journal of Science Communication 12(3): 1-17.

Gunnarson, Brit-Louise (2013) 'Development of medical discourse.' In: Hyland, Ken (ed.) Discourse Studies Reader. London: Bloomsbury, 177-193.

Jensen, Eric (2012) 'Scientific sensationalism in American and British press coverage of therapeutic cloning.' Journalism and Mass Communication Quarterly 89(1): 40-54.

Kitzinger, Jenny (2007) 'Framing and frame analysis.' In: Devereux, Eoin (ed.) Media Studies: Key Issues and Debates. London: Sage, 144-161.

Kitzinger, Jenny and Claire Williams (2005) 'Forecasting science futures: Legitimising hope and calming fears in the embryo stem cell debate.' Social Science and Medicine 61: 731-740.

McLachlan, Shelley and Paul Golding (2000) 'Tabloidization in the British press: A quantitative investigation into changes in British newspapers.' In: Sparks, Collin and John Tulloch (eds.) Tabloid Tales. Oxford: Rowman and Littlefield, 75-90.

McManus, John (1994) Market-driven Journalism. Thousand Oaks: Sage.

Mielby, Henrik, Peter Sandoe and Jesper Lassen (2012) 'The role of scientific knowledge in shaping public attitudes to GM technologies.' Public Understanding of Science 22 (2): 155-168.

Molek-Kozakowska, Katarzyna (2013) 'Towards a pragma-linguistic framework for the study of sensationalism in news headlines.' Discourse \& Communication 7(2): 173-197.

Molek-Kozakowska, Katarzyna (2014) 'Coercive metaphors in news headlines: A cognitive-pragmatic approach.' Brno Studies in English 40(1): 149-173.

Molek-Kozakowska, Katarzyna (2015) 'Pragmalinguistic categories in discourse analysis of science journalism.' Lodz Papers in Pragmatics 11(2): 157-179.

Molek-Kozakowska, Katarzyna (2016) 'Stylistic analysis of headlines in science journalism: A case study of New Scientist.' Public Understanding of Science 1-14 DOI: 10.1177/0963662516637321. 
Montgomery, Martin (2007) The Discourse of Broadcast News. A Linguistic Approach. London: Routledge.

Murawska, Magdalena (2011) 'From a complaint through therapy to recovery: Patient indexicality in medical case reports.' In: Pawlak, Mirosław and Jakub Bielak (eds.) New Perspectives in Language, Discourse and Translation Studies. Berlin and Heidelberg: Springer, 189-199.

O'Connor, Cliodhna and Helene Joffe (2013) 'How has neuroscience affected lay understandings of personhood? A review of evidence.' Public Understanding of Science 22(3): 254-268.

Paltridge, Brian (2013) 'Critical Discourse Analysis.' In: Hyland, Ken (ed.) Discourse Studies Reader, London: Bloomsbury, 89-109.

Pan, Zhongdang and Gerald M. Kosicki (1993) 'Framing analysis: An approach to news discourse.' Political Communication 10: 55-75.

Potter, Jonathan, Margaret Wetherell and Andrew Chitty (1991) 'Quantification rhetoric - cancer on television.' Discourse \& Society 2(3): 333-365.

Weitkamp, Emma (2003) 'British newspapers privilege health and medicine topics over other science news.' Public Relations Review 29(3): 321-333.

\section{Appendix. List of articles (New Scientist, 2013-2015)}

1. Brain damage in American football linked to head trauma 17 October 2013

2. Cyborg gel implant fights diabetes with light 20 October 2013

3. 3D drops raise hopes of cure for baldness 21 October 2013

4. Women's breasts age faster than the rest of their body 22 October 2013

5. Vastly diluted bleach may have protective effect on skin 15 November 2013

6. Cancer meets its nemesis in reprogrammed blood cells 25 November 2013

7. Are Alzheimer's and diabetes the same disease? 28 November 2013

8. Flu vaccine helps unravel complex causes of narcolepsy 19 December 2013

9. Replacement artificial heart keeps first patient alive 31 December 2013

10. High-fibre diet may protect against allergic asthma 06 January 2014

11. Learning drugs reawaken grown-up brain's inner child 08 January 2014

12. Extraordinary stem cell method tested in human tissue 05 February 2014

13. Cure for love: Chemical cures for the lovesick 12 February 2014

14. Cannabis can kill without the influence of other drugs 20 February 2014

15. Bionic arm gives cyborg drummer superhuman skills 06 March 2014

16. First test to predict Alzheimer's years in advance 09 March 2014

17. The therapy pill: Forget your phobia in fast forward 13 March 2014

18. Gunshot victims to be suspended between life and death 26 March 2014

19. Rosacea may be caused by mite faeces in your pores 30 March 2014

20. Engineered vaginas grown in women for the first time 10 April 2014

21. Deaf people get gene tweak to restore natural hearing 23 April 2014

22. Protein that shrinks depressed brains identified 23 April 2014

23. Blood of world's oldest woman hints at limits of life 23 April 2014

24. Bionic pancreas frees people from shackles of diabetes 16 June 2014

25. Human brain's ultimate barrier to open for first time 18 June 2014

26. Diabetes drugs may sometimes do more harm than good 01 July 2014

27. Stem cell treatment causes nasal growth in woman's back 08 July 2014

28. Nerve implant retrains your brain to stop tinnitus 24 July 2014

29. Revealed: How Ebola paralyses the immune system 13 August 2014

30. Young blood to be used in ultimate rejuvenation trial 20 August 2014

31. Artificial sweeteners linked to glucose intolerance 17 September 2014

32. Exercise may be the best anti-ageing pill 10 October 2014 
33. Number of eggs a woman has predicts heart attack risk 20 October 2014

34. Biological litmus paper detects Ebola strains 24 October 2014

35. Guzzling milk might boost your risk of breaking bones 28 October 2014

36. Arachnophobia chopped out of a man's brain 31 October 2014

37. Breast milk stem cells may be incorporated into baby 03 November 2014

38. Monster cancer chromosome is made from shattered DNA 10 November 2014

39. Celebrate your fat - it's fighting off infection 06 January 2015

40. Chronic fatigue syndrome gets yet another name 10 February 2015

41. My drug-filled nanospheres heal at the speed of light 25 February 2015

42. HIV's hiding places at last revealed by simple scan 09 March 2015

43. How many girls mask autism spectrum disorder, like me? 04 March 2015

44. Heart drug reduces risk of cancer spreading 18 March 2015

45. Virus hiding in our genome protects early human embryos 20 April 2015

46. Withdrawal drug could help cannabis addicts kick the habit 06 May 2015

47. Pill of super-protective 'heavy' fat may be key to eternal youth 13 May 2015

48. Life before death: How dying affects living minds 13 May 2015

49. Brain implant allows paralysed man to sip a beer at his own pace 21 May 2015

50. Female "Viagra" could be approved today: what you need to know 4 June 2015

51. Surgeon proposes human head transplant operation as soon as 201712 June 2015

52. Boob tubes: Breast grown in lab will test cancer treatments 12 June 2015

53. Chronic fatigue breakthrough offers hope for millions 1 July 2015

54. Antibody wipeout found to relieve chronic fatigue syndrome 11 July 2015

Katarzyna Molek-Kozakowska, Ph.D., is assistant professor at the Institute of English, Opole University, Poland. Trained as a linguist, she now specializes in discourse analysis and media studies. She has published on various aspects of mass-mediated political discourse, rhetorical and stylistic properties of contemporary journalism and critical literacy.

Address: dr. Katarzyna Molek-Kozakowska, Institute of English, Faculty of Philology, Opole University, Pl. Kopernika 11a, 45-040 Opole, Poland. [email: molekk@uni.opole.pl] 
